\title{
The Relationship among Emotional Leadership, Job Satisfaction and Organizational Commitment: Taking China's Hotel Industry as an Example
}

\author{
Yixing Jin ${ }^{1, a}$, Peiying $\mathrm{Wu}^{1, b^{*}}$, Cheng Lin ${ }^{1, \mathrm{c}}$, Yingda Wang ${ }^{1, \mathrm{~d}}$ \\ ${ }^{1}$ Department of Tourism, Huangshan University, Huangshan City, Anhui Province, 245021, China
}

\begin{abstract}
This study investigated the impact of emotional leadership of leaders on organizational commitment of hotel employees, as well as the mediating role of job satisfaction. The results indicate that: (1) Emotional leadership and job satisfaction have positive effects on organizational commitment. (2) Emotional leadership has a positive effect on job satisfaction. (3) Job satisfaction plays a mediating role between emotional leadership and organizational commitment.
\end{abstract}

\section{INTRODUCTION}

Today's fierce competition among enterprises brings great challenges to leaders and members of organizations. The diverse pressures that employees face in complex work environments lead to burnout, anxiety, depression, and even suicidal behavior. The previous leadership style has been unable to manage employees' emotion effectively. Excellent leaders often work through emotions, and the most effective leaders tend to own higher emotional intelligence. Through emotional transmission, the emotion of leaders can directly affect the emotional state of employees and even the whole team members ${ }^{[1]}$. The study based on model of emotional intelligence ability shows that emotional intelligence can affect people's judgment, memory, creativity and reasoning process ${ }^{[2]}$. Leaders with emotional intelligence can improve job satisfaction, job involvement and organizational commitment of subordinate. The emotional intelligence of leader can not only affect his own performance and effectiveness of lead, but also have a significant positive impact on the job performance and organizational commitment of the subordinate. When employees realize their emotional needs are met, they will have a strong commitment and loyalty to the organization, and be proud of being a member of the organization, and be satisfied with their work. Then the employees will feel that they have the obligation and responsibility to create quality service, which leads to a high organizational commitment.

Based on the important role of emotion in organization, more and more scholars begin to explore the new connotation and characteristics of leadership from the perspective of emotion. In this context, as a new type of leadership, emotional leadership has gradually attracted the attention of academic and business circles, and provides a new path for leader to deal with the emotional crisis in the new era. Emotional leadership is regarded as a multi-faceted and multi-directional lead process, including the effective use of the leader's emotional competence, focusing on emotion-related leader's behaviors, affecting the perception of organization members and enhancing the leadership effectiveness effectively ${ }^{[3]}$. Emotional leadership can influence and manage the emotional state of organizational members, play the beneficial valence of positive emotions effectively, and promote the performance of organizational members and the improvement of organizational performance ${ }^{[4]}$.

In today's global competitive environment, the hotel industry has realized that it must focus on providing excellent service quality and creating customer satisfaction, in order to obtain and retain loyal customer groups, so as to survive and succeed.In the process of providing services to customers, the emotional state of employees will directly affect the service quality and customer satisfaction. Leader should take effective measures to promote the improvement of job satisfaction and organizational commitment of hotel staff, so as to improve the overall performance level of the hotel. In the process of management of employee's emotion, the leader's emotional leadership has become a key factor. This study will explore the influence of emotional leadership on employees' organizational commitment, and analyze the mediating effect of job satisfaction between emotional leadership and organizational commitment. 


\section{LITERATURE REVIEW AND RESEARCH HYPOTHESES}

\subsection{Emotional Leadership, Organizational Commitment and Job Satisfaction}

Research on social networks believes that organizations are made up of interpersonal connections. The classic literature on social networks suggests that individuals are embedded in social networks. Their attitudes and behaviors are restricted by the network. Therefore, social networks can explain the behavior of individuals or groups ${ }^{[5]}$. The internal social network of an organization is not only a channel for information transmission in formal relationships, but also a channel for emotional communication in informal relationships ${ }^{[6]}$. Social networks can influence employees' attitudes and behaviors from two perspectives: information exchange and emotional exchange. The quality of the information and emotions delivered by leaders has an important effect on employee behavior.

Those Leaders with high emotional leadership can spontaneously provide social support to employees, effectively help employees clarify their job goals, provide required work information, clearly define the role of employees in the organization, and actively use their emotions to Influence employees. These behaviors of leaders will make the subordinates aware of the attention of the leader and then promote employees to improve job satisfaction.

In the context of Chinese culture, the influence of leaders on subordinates is greater than that of organizations, and loyalty to people is more important than loyalty to the system. In the implementation process of management measures and management system, leaders with high emotional leadership can timely recognize employees' emotional reactions, and adjust their management methods according to employees' emotional reactions. They can make full use of their emotional abilities to motivate employees to work hard together. Leaders with high emotional intelligence tend to care about others and maintain a positive emotional state. They can create a positive and efficient work environment in the organization, so that employees can reach a higher level of motivation, and produce a strong sense of organizational commitment.

According to previous studies, organizational commitment consists of affective commitment, continuance commitment, normative commitment ${ }^{[7]}$. It has been proved that there is a strong positive relationship between transformational leadership and affective commitment $^{[8]}$. The higher the leader's emotional intelligence, the greater the effectiveness of the leadership. Such emotional leadership will increase the organizational commitment and job satisfaction, and then positively impact the organization's performance ${ }^{[9]}$. From the above statements, the following hypotheses are formed:

H1: Emotional leadership has a significant positive effect on employees' job satisfaction.

H2: Job satisfaction has a significant positive effect on employees' organizational commitment.
H3: Emotional leadership has a significant positive effect on employees' organizational commitment.

\subsection{The Mediating Effect of Job Satisfaction}

Social exchange theory indicated that the exchange between people includes not only material exchange, but also non-material exchange, such as spiritual encouragement, enjoyment, comfort, and acquisition of identity, status and reputation. If employees feel that leaders respect, like, trust or care for themselves, they are willing to pay extra efforts and be more satisfied with their work. Leaders with high emotional leadership have remarkable ability to identify and perceive emotions, and they are adept in accurately recognizing, understanding and effectively regulating employees' emotions to strengthen trust with employees. Through this approach, emotional leadership can enhance employees' perception of being supported, cared for, and respected, so as to strengthen employees' perception of exchange value, and then promote employees to produce higher job satisfaction. Individuals with high job satisfaction are more likely to exhibit emotional dependence and identification with the organization, and then reveal a higher level of organizational commitment.

At present, there are few studies on the relationship between emotional leadership, job satisfaction and organizational commitment, and few studies on the relationship among them at the same time. There is a close relationship between emotional leadership and job satisfaction. A leader with high emotional leadership can promote the positive emotions of the members of the organization, which makes them have emotional dependence and sense of responsibility to the organization. Therefore, this paper believes that job satisfaction plays an important mediating role in the process of leaders' emotional leadership influencing employees' organizational commitment. From the above statements, the following hypotheses are formed:

H4: Employees' job satisfaction plays a mediating role between emotional leadership and organizational commitment.

\section{METHODS}

\subsection{Data Collection}

The subjects of the questionnaire survey were hotel employees from cities such as Shanghai, Nanjing, Hangzhou, Guangzhou and Hefei. The fieldwork lasted more than a month, and a total of 253 questionnaires were distributed. Finally, 231 questionnaires were recovered, with a recovery rate of $91.3 \%$, and 12 invalid questionnaires were eliminated. Finally, 219 questionnaires were used for empirical analysis. The basic situation of the data sample is shown in Table 1. 
TABLE 1. PARTICIPANTS' PROFILE

\begin{tabular}{ccc}
\hline Item & Frequency & percentage \\
\hline Age & & \\
$\leq 30$ & 79 & 29 \\
$31-39$ & 75 & 28 \\
$40-49$ & 89 & 33 \\
$\geq 50$ & 28 & 10 \\
\hline Gender & & \\
Male & 189 & 70 \\
Female & 82 & 30 \\
\hline Graduation & & \\
technical secondary school & 103 & 38 \\
senior high school & 74 & 27 \\
junior college & 74 & 27 \\
undergraduate college & 20 & 7 \\
\hline Tenure & & \\
$\leq 3$ years & 129 & 48 \\
4 - 6 years & 57 & 21 \\
7 - 9 years & 56 & 21 \\
$\geq 10$ years & 29 & 11 \\
\hline Department & & \\
Front Office & 29 & 11 \\
Food \& Beverage & 59 & 22 \\
Housekeeping & 109 & 40 \\
Security & 13 & 5 \\
other departments & 61 & 23 \\
\hline & &
\end{tabular}

\subsection{Measuring Tool}

Based on the Chinese context, emotional leadership is divided into three dimensions which is assessed by 15 items total: Generating employees appropriate emotion, Empathizing with employees and Helping employees handling emotion ${ }^{[10]}$. The Cronbach alpha coefficients of internal reliability in this study were $0.93,0.87$ and 0.90 , respectively.

The Job Satisfaction Scale is a dimension, which contains six items ${ }^{[11]}$. The Cronbach alpha coefficient of internal reliability in this study was 0.92 .

Organizational commitment is divided into three dimensions which assessed by 18 items total: Affective Commitment, Continuance Commitment, Normative Commitment ${ }^{[12]}$. The Cronbach alpha coefficients of internal reliability in this study were $0.90,0.70$ and 0.88 , respectively.

\section{Analysis of the Results}

\subsection{Statistical Description and Correlation Analysis}

According to the data presented in Table 2, Generating employees appropriate emotion is positively correlated with Affective commitment, Continuance commitment, Normative commitment and Job satisfaction $(r=0.51, p<$ $0.01 ; \mathrm{r}=0.24, \mathrm{p}<0.01 ; \mathrm{r}=0.49, \mathrm{p}<0.01 ; \mathrm{r}=0.54, \mathrm{p}<$ 0.01). Empathizing with employees is positively correlated with Affective commitment, Continuance commitment, Normative commitment and Job satisfaction $(\mathrm{r}=0.44, \mathrm{p}<0.01 ; \mathrm{r}=0.15, \mathrm{p}<0.01 ; \mathrm{r}=0.36$, $\mathrm{p}<0.01 ; \mathrm{r}=0.45, \mathrm{p}<0.01)$. Helping employees handling is positively correlated with the Affective commitment, Continuance commitment, Normative commitment and Job satisfaction $(\mathrm{r}=0.40, \mathrm{p}<0.01 ; \mathrm{r}=$ $0.27, \mathrm{p}<0.01 ; \mathrm{r}=0.50, \mathrm{p}<0.01 ; \mathrm{r}=0.51, \mathrm{p}<0.01)$. Job satisfaction is positively correlated with Affective commitment, Continuance commitment, Normative commitment $(\mathrm{r}=0.45, \mathrm{p}<0.01 ; \mathrm{r}=0.24, \mathrm{p}<0.01 ; \mathrm{r}=$ $0.50, \mathrm{p}<0.01)$

TABLE 2. MEANS, STANDARD DEVIATIONS, AND CORRELATIONS OF CORRELATIONS OF OBSERVED VARIABLES

\begin{tabular}{|c|c|c|c|c|c|c|c|c|c|c|c|}
\hline & Mean & SD & 1 & 2 & 3 & 4 & 5 & 6 & 7 & 8 & 9 \\
\hline GEA & 3.71 & 0.62 & 1 & & & & & & & & \\
\hline EWE & 3.68 & 0.59 & $0.79^{* *}$ & 1 & & & & & & & \\
\hline HEH & 3.66 & 0.69 & $0.83^{* *}$ & $0.79^{* *}$ & 1 & & & & & & \\
\hline $\mathrm{AC}$ & 4.01 & 0.59 & $0.51^{* *}$ & $0.44^{* *}$ & $0.40^{* *}$ & 1 & & & & & \\
\hline $\mathrm{CC}$ & 2.98 & 0.77 & $0.24^{* *}$ & $0.15^{*}$ & $0.27^{* *}$ & $0.14^{*}$ & 1 & & & & \\
\hline $\mathrm{NC}$ & 3.78 & 0.56 & $0.49^{* *}$ & $0.36^{* *}$ & $0.50^{* *}$ & $0.41^{* *}$ & $0.49^{* *}$ & 1 & & & \\
\hline EL & 3.68 & 0.59 & $0.94^{* *}$ & $0.92^{* *}$ & $0.94^{* *}$ & $0.48^{* *}$ & $0.24^{* *}$ & $0.47^{* *}$ & 1 & & \\
\hline JS & 2.41 & 0.48 & $0.54^{* *}$ & $0.45^{* *}$ & $0.51^{* *}$ & $0.45^{* *}$ & $0.24^{* *}$ & $0.50^{* *}$ & $0.54^{* *}$ & 1 & \\
\hline OC & 3.94 & 0.58 & $0.53^{* *}$ & $0.40^{* *}$ & $0.50^{* *}$ & $0.64^{* *}$ & $0.78^{* *}$ & $0.82^{* *}$ & $0.51^{* *}$ & $0.51^{* *}$ & 1 \\
\hline
\end{tabular}

${ }^{*} \mathrm{p}<0.05 ;{ }^{* *} \mathrm{p}<0.01$.GEA = generating employees' appropriate emotion; EWE = empathizing with employees;

$\mathrm{HEH}=$ helping employees handling emotion; $\mathrm{AC}=$ Affective Commitment $\mathrm{CC}=$ Continuance Commitment;

$\mathrm{NC}=$ Normative Commitment; $\mathrm{EL}=$ Emotional Leadership; $\mathrm{OC}=$ Organizational commitment; JS $=$ Job satisfaction

\subsection{Confirmatory factor analysis}

Before concrete hypothesis verification, this study used confirmatory factor analysis method in order to examine the validity between variables. The study model contains seven factors: Generating employees appropriate emotion, Empathizing with employees and Helping employees handling emotion, Affective commitment, Continuance commitment, Normative commitment and Job Satisfaction. The structural model has shown a good 
model fit: $\quad \mathrm{x}^{2}(539)=1200.44, \quad \mathrm{p}<0.001 ; \quad \mathrm{x}^{2} / \mathrm{df}=2.23 ; \quad$ TLI=0.90; CFI=0.91; RMSEA $=0.07$.

TABLE 3. RESUlTS OF HIERARCHICAL REGRESSIONS

\begin{tabular}{|c|c|c|c|c|c|c|c|c|c|c|c|c|c|c|c|}
\hline \multicolumn{16}{|c|}{ Dependent variable } \\
\hline & \multicolumn{3}{|c|}{ Job satisfaction } & \multicolumn{4}{|c|}{ Affective Commitment } & \multicolumn{4}{|c|}{ Continuance Commitment } & \multicolumn{4}{|c|}{ Normative Commitment } \\
\hline & \multicolumn{3}{|c|}{ model } & \multicolumn{4}{|c|}{ model } & \multicolumn{4}{|c|}{ model } & \multicolumn{4}{|c|}{ model } \\
\hline & 1 & 2 & 3 & 1 & 2 & 3 & 4 & 1 & 2 & 3 & 4 & 1 & 2 & 3 & 4 \\
\hline & $\beta$ & $\beta$ & $\beta$ & $\beta$ & $\beta$ & $\beta$ & $\beta$ & $\beta$ & $\beta$ & $\beta$ & $\beta$ & $\beta$ & $\beta$ & $\beta$ & $\beta$ \\
\hline \multicolumn{16}{|l|}{ Step 1} \\
\hline Age & -0.03 & -0.04 & -0.05 & 0.06 & 0.05 & 0.03 & 0.04 & $-0.24^{*}$ & $-0.26^{*}$ & $-0.24^{*}$ & $-0.25^{*}$ & -0.01 & -0.03 & -0.03 & -0.03 \\
\hline gender & 0.02 & 0.03 & 0.04 & 0.04 & 0.06 & 0.06 & 0.03 & 0.05 & 0.03 & 0.04 & 0.019 & 0.04 & 0.06 & 0.06 & 0.03 \\
\hline $\begin{array}{c}\text { Graduatio } \\
\text { n }\end{array}$ & -0.01 & -0.01 & 0.02 & 0.06 & 0.06 & 0.09 & 0.09 & 0.06 & -0.01 & -0.01 & -0.01 & -0.06 & -0.05 & -0.03 & -0.03 \\
\hline Tenure & 0.02 & 0.03 & 0.03 & 0.01 & 0.03 & 0.02 & 0.01 & 0.04 & -0.08 & 0.08 & 0.07 & -0.01 & 0.01 & 0.01 & -0.02 \\
\hline $\begin{array}{c}\text { Departme } \\
\text { nt }\end{array}$ & 0.03 & 0.01 & 0.02 & -0.02 & -0.03 & 0.03 & -0.05 & 0.03 & 0.02 & -0.13 & -0.03 & -0.01 & -0.02 & -0.01 & -0.03 \\
\hline \multicolumn{16}{|l|}{ Step 2} \\
\hline GEA & $0.52^{* *}$ & & & $0.47^{* *}$ & & & & $0.28^{* *}$ & & & & $0.46^{* *}$ & & & \\
\hline EWE & & $\begin{array}{c}0.46^{*} \\
*\end{array}$ & & & $0.43^{* *}$ & & & & $0.19^{*}$ & & & & $0.37^{* *}$ & & \\
\hline HEH & & & $\begin{array}{c}0.45^{*} \\
*\end{array}$ & & & $0.34^{* *}$ & & & & $0.30^{* *}$ & & & & $0.42^{* *}$ & \\
\hline JS & & & & & & & $0.44^{* *}$ & & & & $0.30^{* *}$ & & & & $0.48^{* *}$ \\
\hline $\mathrm{R}^{2}$ & 0.31 & 0.22 & 0.28 & 0.27 & 0.21 & 0.19 & 0.22 & 0.1 & 0.06 & 0.12 & 0.1 & 0.26 & 0.16 & 0.28 & 0.27 \\
\hline$\Delta \mathrm{R}^{2}$ & 0.29 & 0.2 & 0.27 & 0.23 & 0.17 & 0.15 & 0.19 & 0.05 & 0.02 & 0.07 & 0.05 & 0.24 & 0.14 & 0.25 & 0.25 \\
\hline $\mathrm{F}$ & 19.37 & 12.23 & 17.26 & 16.2 & 11.72 & 9.98 & 12.89 & 4.59 & $3.08 *$ & 5.72 & 4.73 & 15.49 & 8.51 & 16.71 & 16.51 \\
\hline$\Delta \mathrm{F}$ & $\begin{array}{c}109.9 \\
2 \\
\end{array}$ & 67.79 & 97.45 & 83.86 & 57.94 & 47.91 & 64.75 & 14.11 & 5.47 & 20.55 & 14.89 & 85.57 & 44.48 & 92.69 & 91.51 \\
\hline
\end{tabular}

${ }^{*} \mathrm{p}<0.05 ;{ }^{* *} \mathrm{p}<0.01$. GEA = generating employees' appropriate emotion ; EWE = empathizing with employees; HEH $=$ helping employees handling emotion; JS = job satisfaction

\subsection{Hypotheses testing}

As shown in Table 3, Generating employees appropriate emotion has positive predictive effect on Job $\operatorname{satisfaction}(\beta=0.52, \mathrm{p}<0.01)$, Empathizing with employees has positive predictive effect on Job satisfaction $(\beta=0.46, p<0.01)$ and Helping employees handling emotion has positive predictive effect on Job satisfaction $(\beta=0.45, p<0.01)$, indicating that the higher emotional leadership of leader, the higher the job satisfaction of employee, H1 was verified. Job Satisfaction has positive predictive effect on Affective commitment $(\beta=0.44, p<0.01)$, Job Satisfaction has positive predictive effect on Continuance commitment $(\beta$ $=0.30, \mathrm{p}<0.01)$ and Job Satisfaction emotion has positive predictive effect on Normative commitment $(\beta=$ $0.48, \mathrm{p}<0.01)$, indicating that the higher employee's Job satisfaction, the more inclined the employee is to high Organizational commitment, $\mathbf{H 2}$ was verified.

In addition, Generating employees appropriate emotion has positive predictive effect on Affective $\operatorname{commitment}(\beta=0.47, \mathrm{p}<0.01)$, Empathizing with employees has positive predictive effect on Affective commitment $(\beta=0.43, \mathrm{p}<0.05)$ and Helping employees handling emotion has positive predictive effect on Affective commitment $(\beta=0.34, \mathrm{p}<0.01)$. Generating employees appropriate emotion has positive predictive effect on Continuance commitment $(\beta=0.28, \mathrm{p}<0.01)$, Empathizing with employees has positive predictive effect on Continuance commitment $(\beta=0.19, \mathrm{p}<0.05)$ and Helping employees handling emotion has positive predictive effect on Continuance $\operatorname{commitment}(\beta=0.30, \mathrm{p}$ $<0.01)$. Generating employees appropriate emotion has positive predictive effect on Normative commitment $(\beta=$ $0.46, \mathrm{p}<0.01)$, Empathizing with employees has positive predictive effect on Normative $\operatorname{commitment}(\beta=0.37, \mathrm{p}<$ 0.05 ) and Helping employees handling emotion has positive predictive effect on Normative commitment $(\beta=$ 0.42, $\mathrm{p}<0.01)$. H3 was verified.

The last, as shown in Table 4 , the ratio between the mediation effect and total effect is $0.23 /(0.28+0.23)=$ $45.09 \%$, which indicates that the impact of Emotional leadership on Organizational commitment of employees is realized indirectly through Job satisfaction, $\mathbf{H} 4$ was verified. 
TABLE 4. THE INFLUENCE PATH ANALYSIS OF THE MEDIATION MODEL

\begin{tabular}{lll}
\hline Influence path & Direct impact of standardization & Indirect effect of standardization \\
\hline EL $\rightarrow$ JS & $0.55^{* *}$ & \\
JS $\rightarrow$ OC & $0.41^{* *}$ & $0.23^{* *}$ \\
EL $\rightarrow$ OC & $0.28^{* *}$ &
\end{tabular}

${ }^{*} \mathrm{p}<0.05 ;{ }^{* *} \mathrm{p}<0.01$.

$\mathrm{EL}=$ Emotional Leadership; $\mathrm{OC}=$ Organizational commitment; JS = Job satisfaction

\section{DISCUSSION AND CONCLUSION}

Based on the results of statistical analysis, this study has the following four conclusions. First, emotional leadership of leaders has a positive effect on the job satisfaction of hotel employees. Second, leaders' emotional leadership has a positive effect on the organizational commitment of hotel employees. Third, the job satisfaction of hotel employees has a positive effect on the organizational commitment. Finally, job satisfaction plays a mediating role in the relationship between emotional leadership and organizational commitment.

In summary, through the study and discussion on the relationship among emotional leadership, job satisfaction and organizational commitment, we suggest that the future hotel development should pay attention to the emotional interaction between leaders and employees, build a productive relationship of psychological contract between leaders and hotel employees, and make full use of the mediating role of job satisfaction to improve employees' organizational commitment.

For the hotel employees, the emotional leadership of leaders is particularly important. Hotel employees expend a lot of energy every day to deal with external emotional expectations. They are typical emotional workers. In the working environment, they need more emotional support and care. At this time, the positive role of the leader's emotional leadership will come into play. The effective emotional regulation and management of the leaders will promote the enthusiasm of employees and help them involve themselves in the job. Emotional leadership is not only a trait, but also a skill. Therefore, in specific practice, organizations should pay attention to the recruitment and selection of leaders on the one hand, and the cultivation and development of leaders' emotional leadership on the other. In the process of selecting leaders, organizations should take emotional leadership as an evaluation indicator. Emotional leadership, as an individual's ability to process emotional information, can be cultivated and developed the day after tomorrow. Therefore, organizations should attach importance to the development of leaders' emotional leadership. While improving their own emotional leadership, leaders should pay attention to forming and creating a good emotional atmosphere, and pay attention to affecting employees' organizational commitment and work performance through employee satisfaction.

\section{ACKNOWLEDGMENT}

This work was supported by the Science Foundation of Anhui Educational Committee (Grant NO. SK2016A0883 \& SKHS2019B12), the Scientific Foundation of tourism talents training demonstration base in Anhui Province (Grant NO. YYRCYB1706) and the Talent Startup Project of Huangshan university (Grant NO. 2015xskq002).

\section{REFERENCE}

1. Naureen B. Relationship Between Mood and Susceptibility to Emotional Contagion: Is Positive Mood More Contagious?[J]. North American Journal of Psychology, 2012, 14(3): 517-529.

2. Mayer J. D. A new field guide to emotional intelligence $[\mathrm{J}]$. Emotional intelligence in everyday life, 2006, 2(1): 3-26.

3. Humphrey R. H. The many faces of emotional leadership $[\mathrm{J}]$. The Leadership Quarterly, 2002, 13(5):493-504.

4. Kaplan S., Cortina J., Ruark G. \& LaPort K. \& Nicolaides, V. The role of organizational leaders in employee emotion management: A theoretical model[J]. Leadership Quarterly, 2014, 25(3):563-580.

5. Wellman B. \& Berkowitz S. D. Social Structures: A Network Approach[J]. American Political Science Association, 1988, 83(4).

6. Gibbons D. E. Friendship and Advice Networks in the Context of Changing Professional Values[J]. Administrative Science Quarterly, 2004, 49(2): 238-262.

7. Meyer J. P. \& Allen N. J. A three-component conceptualization of organizational commitment[J]. Human resource management review, 1991, 1(1): 61-89.

8. Bycio P., Hackett R. D. \& Allen J. S. Further assessments of Bass's (1985) conceptualization of transactional and transformational leadership[J]. Journal of Applied Psychology, 1995.

9. Avolio B. J., Gardner W. L., Walumbwa F. O., Lithans F. \& May D. R. Unlocking the mask: a look at the process by which authentic leaders impact follower attitudes and behaviors[J]. Leadership Quarterly, 2004, 15(6):801-823.

10. Haiqiong Z. Research on the Influence Mechanism 
of Emotional Leadership on Innovation Performance[D]. Guangzhou University, 2016.

11. Curry J. P., Wakefield D. S., Price J. L., et al. On the causal ordering of job satisfaction and organizational commitment [J]. Academy of management journal, 1986, 29(4): 847-858.

12. Meyer J. P. \& Allen N. J. Commitment in the workplace[J]. Thousand Oaks, CA: Sage, 1997: 7-65 